\title{
Alpha-lipoic acid as a new treatment option for Azheimer type dementia
}

\author{
Klaus Hager a,*, Andres Marahrens a, Marlene Kenklies a, \\ Peter Riederer ${ }^{\mathrm{b}}$, Gerald Münch ${ }^{\mathrm{c}}$ \\ a Department of Medical Rehabilitation and Geriatrics, Henriettenstiftung, Schwemannstraße 19, \\ D-30559 Hannover, Germany \\ ${ }^{\mathrm{b}}$ Department of Psychiatry, University of Würzburg, Fuechsleinestrasse 15, \\ D-97080 Würzburg, Germany \\ c Neuroimmunological Cell Biology, IZKF, University of Leipzig, Johannisalle 30a, \\ D-ö4ö31 Leipzig, Germany
}

Received 29 November 2000; received in revised form 26 February 2001; accepted 28 February 2001

\begin{abstract}
Oxidative stress and energy depletion are characteristic biochemical hallmarks of Alzheimer's disease (AD), thus antioxidants with positive effects on glucose metabolism such as thioctic ( $\alpha$-lipoic) acid should exert positive effects in these patients. Therefore, $600 \mathrm{mg}$ $\alpha$-lipoic acid was given daily to nine patients with $\mathrm{AD}$ and related dementias (receiving a standard treatment with acetylcholinesterase inhibitors) in an open study over an observation period of, on avarage, $337 \pm 80$ days. The treatment led to a stabilization of cognitive functions in the study group, demonstrated by constant scores in two neuropsychological tests (mini-mental state examination: MMSE and AD assessment scale, cognitive subscale: ADAScog). Despite the fact that this study was small and not randomized, this is the first indication that treatment with $\alpha$-lipoic acid might be a successful 'neuroprotective' therapy option for AD and related dementias. C 2001 Published by Elsevier Science Ireland Ltd. All rights reserved.
\end{abstract}

Keywords: $\alpha$-Lipoic acid; Alzheimer's disease; Dementia; Treatment of AD

* Corresponding author. Tel:: + 49-511-2893222; fax: + 49-511-2893004.

E-mail address: geriatre.hannover@t-online.de (K. Hager). 


\section{Introduction}

Alzheimer-type dementia (AD) is the most common cause of dementia among people aged 65 years and older. It represents a major health problem particularly in the developed countries, because of its enormous impact on individuals, families, the health care system, and society as a whole. It is estimated that up to 4 million people currently suffer from the disease in the USA, and that the prevalence doubles every 5 years beyond the age of $65(\mathrm{NIH}, 1999)$. In order to address the problem of dementia, an out-patient memory clinic was founded in 1995 as a cooperation of the hospital's neurological and the geriatric department (Hager et al., 1998). Diagnosis, especially in the early stages, and treatment of dementia are the main activities, but also several caregiver and patient training groups have been initiated.

In 1997, a 74 year old patient presented herself with signs of cognitive impairment. Diabetes mellitus and a mild form of polyneuropathy were its main concomittant diseases. With clinical criteria of DSM-III-R (APA, 1987) deficits in the neuropsychological tests, a NMR without signs of ischemia and a typical SPECT with a decreased perfusion bi-temporal and bi-parietal, as well as the exclusion of other underlying diseases, the diagnosis of an AD in an early stage was established and a treatment with acetylcholinesterase inhibitors was initiated. Due to the polyneuropathy, the patient received $600 \mathrm{mg} \alpha$-lipoic acid per day. Since then, several re-tests have been performed, which showed no substantial decline of the cognitive functions. Therefore, the diagnosis of mild AD was reevaluated several times, but the diagnostic features did not change and the neuropsychological tests kept on showing no further cognitive impairment. A large epidemiological investigation suggested a positive correlation of type 2 diabetes mellitus with late onset AD (Ott et al., 1999). There are, however, opposite results from other studies (Curb et al., 1999; Tariot et al., 1999).

Taking into account that $\alpha$-lipoic acid might attenuate free radical damage as well as reduce inflammatory activities and hence might have a positive effect on neuronal damage and might thus explain the lack of progression, it was decided to test $\alpha$-lipoic acid in an open clinical study with a small group of patients who were currently being treated by our department. Our aim was to confirm or discard the possibility of an influence of $\alpha$-lipoic acid on the progression of neurodegenerative forms of dementia.

\section{Patients and methods}

The study was designed as an open, non-randomized investigation (Table 1). Subjects with probable AD underwent an evaluation using clinical interview, mental status assessment, physical and neurological examinations. All participants met the criteria of DSM-III-R (APA, 1987) for probable AD. Subjects were required to be aged 45 years or older. Patients with early onset and a history suggesting a familial form of AD were excluded. Informed consent was obtained 
Table 1

A list of the methods

Open clinical study

Nine patients of the memory department in Hanover

With a primary degenerative form of dementia

Mild to moderate degree of dementia

Additionally to an acetylcholinesterase inhibitor (Aricept ${ }^{\circledR}$, Exelon ${ }^{\circledR}$ )

No further modification of the medication

Consent from patient and caregiver

Consent from the local ethics commitee

from each subject, the caregiver or the legal guardian. The study was approved by the institutional review board. Patients received the standard treatment of either donepezil or rivastigmin at least 3 months prior to starting with thioctic acid treatment, which was given once daily in a dose of $600 \mathrm{mg}$, administered in the morning, $1 \mathrm{~h}$ before breakfast.

For assessing cognitive performance, the mini-mental state examination (MMSE) (Folstein et al., 1975), and the cognitive subscale of the AD assessment scale (ADAScog) (Rosen et al., 1984) were applied. During the last 12 months, nine patients were included in the study (Table 2). According to the findings with the treatment of the acetylcholinesterase inhibitors, only patients with mild to moderate dementia (MMSE 17 points or higher) were accepted in this study.

\section{Results}

The nine patients included in our study were tested by means of MMSE and ADAScog several times prior to and after the start of the treatment with $\alpha$-lipoic acid (Table 3). When the patients first came to the memory department, their cognitive impairment was mild to moderate. Before starting treatment with $\alpha$-lipoic acid, despite cognitive training, as well as treatment with acetylcholinesterase inhibitors, the test results showed a constant decline. With a decrease of two points in the MMSE per year and an increase of four points in the ADAScog, this decline was relatively small compared to data from the literature (Stern et al., 1994a,b). After initiating treatment with $\alpha$-lipoic acid, the test results remained constant over the period of nearly 1 year of monitoring (Table 3; Fig. 1).

Table 2

Charateristics of the study population

$\begin{array}{ll}\text { Number } & \text { Nine (eight men, one woman) } \\ \text { Age } & 52-81(67 \pm 9) \text { years } \\ \text { Dementia known since } & 1.3-4.0(2.9 \pm 1.0) \text { years } \\ \text { MMSE scores (when diagnosed first) } & 19-25(23 \pm 2) \\ \text { ADAScog scores (when diagnosed first) } & 12-26(19 \pm 5)\end{array}$


Table 3

Neuropsychological testing before and after treatment with $\alpha$-lipoic acid

\begin{tabular}{lcll}
\hline Test (no) & $\begin{array}{l}\text { Time in relation to the start of } \alpha \text {-lipoic acid } \\
\text { (days) }\end{array}$ & MMSE Scores & ADAS Scores \\
\hline 1 & $-687 \pm 326$ & $23 \pm 2$ & $19 \pm 5$ \\
2 & $-164 \pm 130$ & $20 \pm 2$ & $22 \pm 6$ \\
3 & $-12 \pm 116$ & $19 \pm 1$ & $27 \pm 12$ \\
4 & $131 \pm 115$ & $19 \pm 2$ & $27 \pm 12$ \\
5 & $243 \pm 94$ & $20 \pm 3$ & $26 \pm 11$ \\
6 & $337 \pm 80$ & $20 \pm 4$ & $27 \pm 10$ \\
\hline
\end{tabular}

\section{Discussion}

Part of the pathophysiological process in the Alzheimer-type of dementia is due to chronic inflammatory reactions (McGeer and McGeer, 1999). One of the factors triggering inflammation are advanced glycation endproducts (AGEs), which can be found in senile plaques (Münch et al., 1997). A role of oxidative damage in amyloid beta protein precursor-mediated cell death in cell cultures has also been suggested (Sopher et al., 1996). Microglia and astroglia try in vain to degrade senile plaques, thereby generating free radicals as well as proinflammatory cytokines like interleukin 1 and 6, but also tumor-necrosis factor alpha (TNF- $\alpha$ ). Thereby adjacent nervous tissue is damaged (Neumann et al., 1999). In addition to these inflammatory processes other factors, like an age- and stress-dependent energy deficit, contribute to the diminished ability of the neurons to cope with free radicals as well as to repair damaged structures (Blum-Degen et al., 1995; Hoyer, 1991).

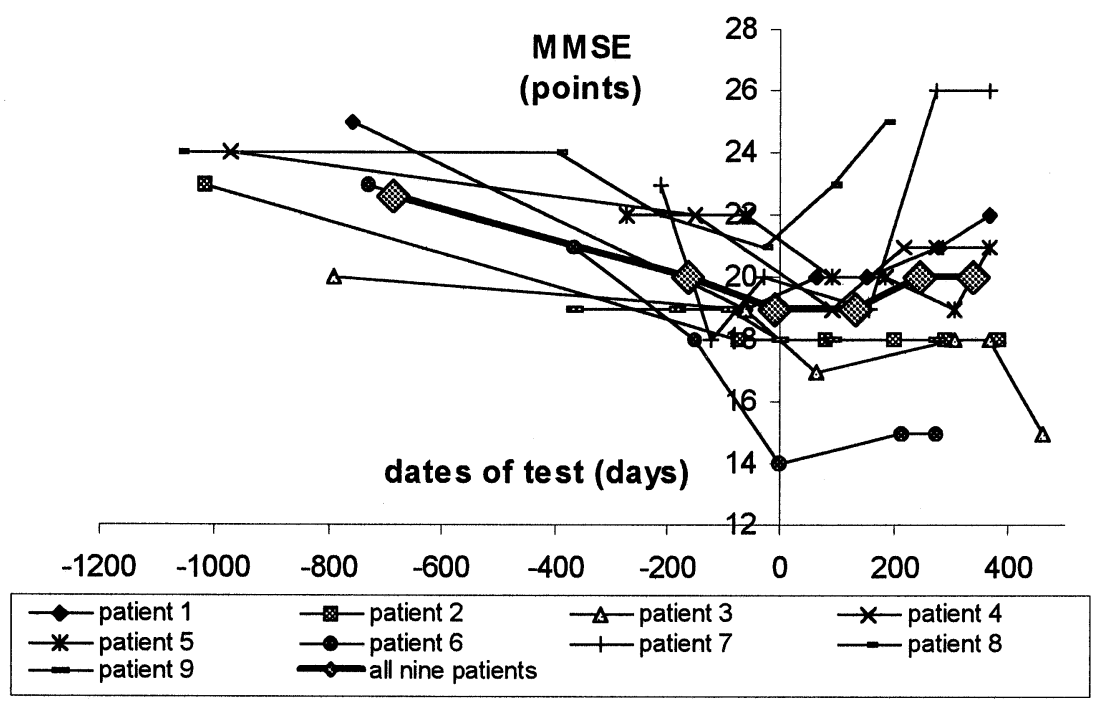

Fig. 1. MMSE before and after therapy with lipoic acid (treatment start: day 0). 
Table 4

Possible mechanisms of $\alpha$-lipoic acid

Influence on neuronal energy production

Reactivation of enzymes of glucose metabolism (esp. pyruvate dehydrogenase)

Reactivation of glucose transport

$\rightarrow \quad$ Increase of acetyl-CoA and ATP production

$\rightarrow \quad$ Increase of neurotransmitter synthesis

Anti-oxidative and anti-inflammatory

o Scavenger of free radicals and carbonyls (precursors of AGE)

$\rightarrow \quad$ Down regulation of chronic inflammatory processes in the vicinity of amyloid plaques

The subsequent decline in central cholinergic neurotransmission has lead to the development of the first generation of drugs against AD, the acetylcholinesterase inhibitors. But these drugs only offer a symptomatic approach and are of limited effect in long term administration. Other drugs have been reported to at least delay the progression of AD, like indomethacin (McGeer and McGeer, 1999; Rogers et al., 1993), selegilin and vitamin E (Sano et al., 1997), suggesting that anti-inflammatory and antioxidant agents can be beneficial in the treatment of AD patients.

Since expression of many of the relevant proinflammatory cytokines is regulated by redox-sensitive signal transduction pathways, membrane permeable antioxidants can act as both anti-inflammatory and antioxidant agents. Among those drugs, $\alpha$-lipoic acid, which has also been reported to have a beneficial effect on impaired glucose metabolism and is, therefore, licenced for the treatment of diabetic neuropathy, was chosen for an open pilot trial with AD patients.

$\alpha$-Lipoic acid is an essential cofactor in the multienzyme complexes of $\alpha$-ketoacid-dehydrogenases such as pyruvate-, $\alpha$-keto-glutarate- and branched chain $\alpha$ keto-acid-dehydrogenases (Schmidt et al., 1965). $\alpha$-Lipoic acid is a strong antioxidant (Packer et al., 1995) and interacts with reactive oxygen species (ROS), such as superoxide radicals, hydroxyl radicals, hypochloric acid, peroxyl radicals, and singlet oxygen (Biewanga et al., 1997). It also protects membranes by interacting with vitamin $\mathrm{C}$ and glutathione, which may in turn recycle vitamin $\mathrm{E}$ (Packer, 1992).

$\alpha$-Lipoic acid may act in various ways (Table 4). Advanced glycation endproducts (AGE)-dependent signal transduction uses free radicals as intracellular 'second messengers'. $\alpha$-Lipoic acid is an antioxidant, which penetrates cell membrane and can act intracellularly (Bierhaus et al., 1997). Neuroprotective properties of the substance, e.g., a decrease of the effect of neurotoxins, have been demonstrated in cell culture systems (Loske et al., 1998; Packer et al., 1997). $\alpha$-Lipoic acid increases glucose metabolism, e.g. by enhancing glucose transport and activity of the pyruvate dehydrogenase. This results in an increase of the intracellular energy production (Estrada et al., 1996), which in turn, has positive effects on neurotrans- 
mitter synthesis. Antioxidant and antiinflammatory effects have also been postulated. The positive effects of $\alpha$-lipoic acid on glucose metabolism and energy balance may also play an important role in the functioning of the neurons. Therefore, the importance of $\alpha$-lipoic acid in the treatment of dementia was proposed as early as 1998 (Loske et al., 1998; Münch et al., 1998).

Up to now, only few data concerning the use of $\alpha$-lipoic acid in the treatment of dementia have been published. In HIV-associated dementia, the mechanism of which widely differs from that in AD, no effect has been found (Dana Consortium, 1998). $\alpha$-Lipoic acid decreased neurotoxicity of L-homocysteinic acid in embryonic rat nerve cell cultures (Lockhart et al., 2000).

The data in this study show that the deterioration of cognitive functions came to a halt for an average of at least 337 days (Table 3Fig. 1)). Without a drug effect, the decline of the MMSE should have been two points within 1 year and the increase of the ADAScog should have amounted to about six-nine points per year (Stern et al., 1994a,b). Explanations other than the treatment effect of $\alpha$-lipoic acis are less probable. The patients had attended the memory department at least since the start of the acetylcholinesterase inhibitors, so that changes of the psycosocial situation of the patients and their caregivers were improbable. The inhibitors of acetylcholineesterase had been in use for an average of 238 days. The cognitive improvement, i.e., of Donepezil, returns to baseline after an average of 38 weeks (Rogers and Friedhoff, 1998), so that a treatment effect of these drugs also seems less likely. No persons with diabetes mellitus were part of the study population.

Although this open clinical study has to be substantiated with a double blind trial including a larger number of subjects and additional criteria, the results of our pilot trial are a first hint that $\alpha$-lipoic acid might have positive effects on the course of Alzheimer-type dementia, at least when given as adjuvans to the standard medication consisting of acetylcholinesterase inhibitors. Further advantages of thioctic acid are its minimal side effects, its relatively low price and its availability through various manufacturers.

There is a clear and widely recognised need to investigate the effects of antioxidants on $\mathrm{AD}$ in randomised, placebo-controlled, double-blind trials (Flynn and Ranno, 1999). Taking into account the present lack of such studies, clinical observations as the one presented here, not yet confirmed by a randomised study design, may nevertheless warrant publication.

\section{Acknowledgements}

The authors are indebted to all patients and caregivers for their support as well as to Dr H.-J. Kremer from ASTA Medica AG for contribution of literature. This work was supported by the Alzheimer Forschung International (AFI), and the Bundesministerium für Bildung, Forschung und Technologie (BMBF), Interdisziplinäres Zentrum für Klinische Forschung (IZKF) at the University of Leipzig (01KS9504, Project N1) (to G.M.). 


\section{References}

APA (American Psychiatric Association), 1987. Diagnostic and Statistical Manual of Mental Dis-orders, 3rd, revised (DSM-III-R). APA Press, Washington, D.C.

Bierhaus, A., Chevion, S., Chevion, M., Hofmann, M., Quehenberger, P., Illmer, T., et al., 1997. Advanced glycation end product-induced activation of TNF-kappaB is suppressed by $\alpha$-lipoic acid in cultured endothelial cells. Diabetes 46, 1481-1490.

Biewanga, G., Vriesmann, M.F., Haenen, G.R.M.M., Bast, A., 1997. The identification of a new metabolite of lipoic acid in man: 3-ketolipoic acid. In: Biewanga, G. (Ed.), Lipoic Acid: a Pharmacochemical Study (Thesis). Vrije Universiteit, Amsterdam, The Netherlands, pp. 137-152.

Blum-Degen, D., Frölich, L., Hoyer, S., Riederer, P., 1995. Altered regulation of brain glucose meta-bolism as a cause of neurodegenerative disorders? J. Neural. Transm. 46 (Suppl.), 139-147.

Curb, J.D., Rodriguez, B.L., Abbott, R.D., Petrovitch, H., Ross, G.W., Masaki, K.H., et al., 1999. Longitudinal association of vascular and Alzheimer's dementias, diabetes, and glucose tolerance. Neurology 52, 971-975.

Dana Consortium on the Therapy of HIV Dementia and Related Cognitive Disorders, 1998. A randomized, double-blind, placebo-controlled trial of deprenyl and thioctic acid in human immunodeficiency virus-associated cognitive impairment. Neurology 50, 645-651.

Estrada, D.E., Ewart, H.S., Tsakiridis, T., Volchuk, A., Ramlal, T., Tritschler, H., Klip, A., 1996. Stimulation of glucose uptake by the natural coenzyme alpha-lipoic acid thioctic acid - participation of elements of the insulin signalling pathway. Diabetes 45, 1798-1804.

Flynn, B.L., Ranno, A.E., 1999. Pharmacologic management of Alzheimer disease, Part II: Antioxidants, antihypertensives, and ergoloid derivatives. Ann. Pharmacother. 33, 188-197.

Folstein, M.F., Folstein, S.E., McHugh, P.R., 1975. Mini-mental state: a practical method for grading the cognitive state of patients for the clinician. J. Psychiatr. Res. 12, 189-198.

Hager, K., Haferkamp, G., Marahrens, A., Kenklies, M., 1998. Interdisziplinäre Gedächtnissprechstunde. Hannover. Med. Welt. (in German) 49, 592-597.

Hoyer, S., 1991. Abnormalities of glucose metabolism in Alzheimer's disease. Ann. NY Acad. Sci. 640, $53-58$.

Lockhart, B., Jones, C., Cuisinier, C., Villain, N., Peyroulan, D., Lestage, P., 2000. Inhibition of 1-homocysteic acid and buthionine sulphoximine-mediated neurotoxicity in rat embryonic neuronal cultures with alpha-lipoic acid enantiomers. Brain Res. 855, 292-297.

Loske, C., Neumann, A., Cunningham, A.M., Nichol, K., Schinzel, R., Riederer, P., Münch, G., 1998. Cytotoxicity of advanced glycation end-products is mediated by oxidative stress. J. Neural. Transm. 105, 1005-1015.

McGeer, E.G., McGeer, P.L., 1999. Brain inflammation in Alzheimer disease and the therapeutic implications. Curr. Pharm. Des. 5, 821-836.

Münch, G., Thome, J., Foley, P., Schinzel, R., Riederer, P., 1997. Advanced glycation endproducts in ageing and Alzheimers disease. Brain Res. Rev. 23, 134-143.

Münch, G., Schinzel, R., Loske, C., Wong, A., Durany, N., Li, J.J., Vlassara, H., Smith, M.A., Perry, G., Riederer, P., 1998. Alzheimer's disease — synergistic effects of glucose deficit, oxidative stress and advanced glycation endproducts. J. Neural. Transm. 105, 439-461.

NIH (National Institute of Health, 1999, Progress Report on Alzheimer's Disease. NIH Publication No. 99-4664; www.alzheimers.org/pubs/pr99.htm.

Neumann, A., Schinzel, R., Palm, D., Riederer, P., Munch, G., 1999. High molecular weight hyalu-ronic acid inhibits advanced glycation endproduct-induced NF-kappaB activation and cytokine expression. FEBS Letters 453, 283-287.

Ott, A., Stolk, R.P., Van Harskamp, F., Pols, H.A., Hofman, A., Breteler, M.M., 1999. Diabetes mellitus and the risk of dementia: The Rotterdam Study. Neurology 53, 1937-1942.

Packer, L., 1992. Interactions among antioxidants in health and disease: Vitamin E and its redox cycle. Proc. Soc. Exp. Biol. Med. 200, 271-276.

Packer, L., Witt, E.H., Tritschler, H.J., 1995. Alpha-lipoic acid as a biological antioxidant. Free. Rad. Biol. Med. 19, 227-250. 
Packer, L., Tritschler, H.J., Wessel, K., 1997. Neuroprotection by the metabolic antioxidant alpha-lipoic acid. Free Radical Biol. Med. 22, 359-378.

Rogers, S.L., Friedhoff, L.T., 1998. Long-term efficacy and safety of donepezil in the treatment of Alzheimer's disease: an interim analysis of the results of a US multicentre open label extension study. Eur. Neuropsychopharmacol. 8, 67-75.

Rogers, J., Kirby, L.C., Hempelman, S.R., Berry, D.L., McGeer, P.L., Kaszniak, A.W., Zalinski, J., Cofield, M., Mansukhani, L., Willson, P., 1993. Clinical trial of indomethacin in Alzheimer's disease. Neurology 43, 1609-1611.

Rosen, W.G., Mohs, R.C., Davis, K.L., 1984. A new rating scale for Alzheimer's disease. Am. J. Psychiatr. 141, 1356-1364.

Sano, M., Ernesto, C., Thomas, R.G., Klauber, M.R., Schafer, K., Grundman, M., et al., 1997. A controlled trial of selegiline, alpha-tocopherol, or both as treatment for Alzheimer's disease. The Alzheimer's Disease Cooperative Study. New Engl. J. Med. 336, 1216-1222.

Schmidt, P., Grafen, P., Goedde, H.W., 1965. Chemie und Biochemie der Alpha-Liponsäure. Angew. Chemie (in German) 77, 900-911.

Sopher, B.L., Fukuchi, K., Kavanagh, T.J., Furlong, C.E., Martin, G.M., 1996. Neurodegenerative mechanisms in Alzheimer disease. A role for oxidative damage in amyloid beta protein precursor-mediated cell death. Mol. Chem. Neuropathol. 29, 153-168.

Stern, R.G., Mohs, R.C., Davidson, M., Schmeidler, J., Silverman, J., Kramer-Ginsberg, E., Searcey, T., Bierer, L., Davis, K.L., 1994a. A longitudinal study of Alzheimer's disease: measurement, rate, and predictors of cognitive deterioration. Am. J. Psychiatry 151, 390-396.

Stern, Y., Albert, M., Brandt, J., Jacobs, D.M., Tang, M.X., Marder, K., et al., 1994b. Utility of extrapyramidal signs and psychosis as predictors of cognitive and functional decline, nursing home admission, and death in Alzheimer's disease: prospective analyses from the Predictors Study. Neurology 44, 2300-2307.

Tariot, P.N., Ogden, M.A., Cox, D., Williams, T.F., 1999. Diabetes and dementia in long-term care. J. Am. Geriatr. Soc. 47, 423-429. 